\title{
Phenolic compounds apigenin, hesperidin and kaempferol reduce in vitro lipid accumulation in human adipocytes
}

\author{
Saioa Gómez-Zorita ${ }^{1,3}$, Arrate Lasa ${ }^{1,3^{*}}$ C Naiara Abendaño ${ }^{1}$, Alfredo Fernández-Quintela1,3, \\ Andrea Mosqueda-Solís', Maria Pilar Garcia-Sobreviela², Jose M. Arbonés-Mainar ${ }^{2,3}$ and Maria P. Portillo ${ }^{1,3}$
}

\begin{abstract}
Background: Adipocytes derived from human mesenchymal stem cells (MSCs) are widely used to investigate adipogenesis. Taking into account both the novelty of these MSCs and the scarcity of studies focused on the effects of phenolic compounds, the aim of the present study was to analyze the effect of apigenin, hesperidin and kaempferol on pre-adipocyte and mature adipocytes derived from this type of cells. In addition, the expression of genes involved in TG accumulation was also measured.
\end{abstract}

Methods: Pre-adipocytes were cultured from day 0 to day 8 and mature adipocytes for $48 \mathrm{~h}$ with the polyphenols at doses of 1,10 and $25 \mu \mathrm{M}$.

Results: Apigenin did not show an anti-adipogenic action. Pre-adipocytes treated with hesperidin and kaempferol showed reduced TG content at the three experimental doses. Apigenin did not modify the expression of the main adipogenic genes (c/ebp $\beta$, c/ebpa, ppary and srebp 1c), hesperidin inhibited genes involved in the three phases of adipogenesis (c/ebp $\beta$, srebp 1c and perilipin) and kaempferol reduced c/ebp $\beta$. In mature adipocytes, the three polyphenols reduced TG accumulation at the dose of $25 \mu \mathrm{M}$, but not at lower doses. All compounds increased mRNA levels of atgl. Apigenin and hesperidin decreased fasn expression. The present study shows the anti-adipogenic effect and delipidating effects of apigenin, hesperidin and kaempferol in human adipocytes derived from hMSCs. While hesperidin blocks all the stages of adipogenesis, kaempferol only inhibits the early stage. Regarding mature adipocytes, the three compounds reduce TG accumulation by activating, at least in part, lipolysis, and in the case of hesperidin and apigenin, also by reducing lipogenesis.

Conclusions: The present study shows for the first time the anti-adipogenic effect and delipidating effect of apigenin, hesperidin and kaempferol in human adipocytes derived from MSCs for the first time.

Keywords: Adipocytes, Apigenin, Hesperidin, Kaempferol, Obesity, Human mesenchymal stem cells

\section{Background}

Overweight and obesity are considered a serious threat to public health, due to their high prevalence in our society and their association with co-morbidities such as type 2 diabetes, hypertension and cardiovascular diseases $[1,2]$.

\footnotetext{
*Correspondence: arrate.lasa@ehu.eus

${ }^{1}$ Nutrition and Obesity Group, Department of Nutrition and Food Science and Lucio Lascaray Research Center, University of the Basque Country (UPV/EHU), Vitoria, Spain

Full list of author information is available at the end of the article
}

In vitro studies performed using adipocytes derived from human mesenchymal stem cells (MSCs) represent a good method to analyze the two main processes that lead to adipose tissue increase and thus, to obesity development: hypertrophy (increased adipocyte size) and hyperplasia (increased adipocyte number) [1, 2]. MSCs are fibroblastoid multipotent adult stem cells with a high capacity for self-renewal. These cells have been isolated from several human tissues, such as bone marrow, adipose tissue, umbilical cord matrix, tendon, lung and periosteum, among others [3]. MSCs become adipoblasts, 
which subsequently commit to pre-adipocytes. Thereafter, upon adipogenic stimuli, pre-adipocytes undergo terminal differentiation into mature adipocytes [4]. Recently, it has been suggested that MSCs are a main source of adipocyte generation. Therefore, the biology of MSCs is studied in this work, as is the possible roles of MSCs in managing different components of metabolic syndrome [5-7].

In recent years, a great deal of attention has been paid to new active biomolecules that could be effective in preventing or treating obesity and its co-morbidities. Numerous studies have been carried out with phenolic compounds, which are members of a very large family of plant-derived compounds in the form of a wide variety of chemical structures [8]. Of these, resveratrol, quercetin and epigallocatechin have been shown to prevent fat accumulation in adipocytes through different mechanisms: by adipogenesis and lipogenesis inhibition as well as by lipolysis and fatty acid oxidation stimulation [9-11]. It must be pointed out that the majority of these studies have been performed in 3T3-L1 or mouse and rat primary adipocytes. However, studies demonstrating the effect of these phenolic compounds on human adipocytes are scarce to date [12-19]. Furthermore, important differences in adipocyte function exist among species, which complicates the extrapolation of results from murine adipocytes to human adipocytes [20]. Consequently, human MSCs provide an important alternative model system which represents a valuable instrument for experimental human fat cell investigation [21,22].

Taking into account the novelty of these MSCs as an in vitro model for the study of obesity, and the few studies performed on human cells with phenolic compounds, the aim of the present study was to analyze the effect of three polyphenols (two flavonoids: apigenin and hesperidin; and one non-flavonoid: kaempferol). These polyphenols were previously studied in 3T3-L1 cells in our laboratory [23], in pre-adipocyte and mature adipocytes derived from this type of cells. In addition, the expression of genes involved in TG accumulation was also measured.

\section{Methods \\ Cell samples}

Human mesenchymal fat cells (hMSCs) were obtained from subcutaneous abdominal fat from a 59 year-old man with overweight and without type 2 diabetes mellitus, hypertension or dyslipidemia or obesity, as previously described [24], and approved by Clinical Investigation Ethics Committee of Aragon (Acta 11/2013).

\section{Experimental design}

Cells were cultured until confluence in DMEM $1 \mathrm{~g} / \mathrm{L}$ glucose (Lonza, Verviers, Belgium) containing 10\% fetal bovine serum (FBS), $1 \mathrm{mM}$ sodium pyruvate, $4 \mathrm{mM}$ glutamine, $1 \%$ penicillin/streptomycin. Differentiation was induced 2 days post-confluence (designated as day 0 ) with DMEM 4.5 g/L glucose (Lonza, Verviers, Belgium) supplemented with 10\% FBS, $1 \mu \mathrm{M}$ dexamethasone, $0.5 \mathrm{mM}$ isobutylmethylxanthine, $1 \mu \mathrm{M}$ rosiglitazone and $1.67 \mu \mathrm{M}$ human insulin. This medium was changed every $72 \mathrm{~h}$. At day 6, cells were incubated in a DMEM $4.5 \mathrm{~g} / \mathrm{L}$ glucose medium (Lonza, Verviers, Belgium) containing $1 \mathrm{mM}$ sodium pyruvate, $4 \mathrm{mM}$ glutamine, 10\% FBS, $1 \%$ penicillin/streptomycin and this medium was changed every $72 \mathrm{~h}$ until cells were treated. Cells were maintained at $37{ }^{\circ} \mathrm{C}$ in a humidified $5 \% \mathrm{CO}_{2}$ atmosphere. Each experiment was performed three times.

Differentiating cells were grown in 6-well plates and incubated together with either $0.1 \%$ ethanol (95\%) (control group) or with apigenin (Extrasynthese, Lyon, France), hesperidin (Extrasynthese, Lyon, France) or with kaempferol (Genay, Lyon, France) at 1, 10 or $25 \mu \mathrm{M}$ (diluted in $95 \%$ ethanol). In a first experiment, on day 3 cells treated with phenolic compounds were used at $25 \mu \mathrm{M}$ for TG content determination and RNA extraction. In a second experiment, on day 8 cells treated with phenolic compounds were used at 1,10 or $25 \mu \mathrm{M}$ for TG content determination and cells treated with $25 \mu \mathrm{M}$ were used for RNA extraction and cytotoxicity determination.

Mature adipocytes grown in 6-well plates were also incubated with either $0.1 \%$ ethanol (95\%) (control group) or with apigenin, hesperidin or kaempferol at 1,10 or $25 \mu \mathrm{M}$ (diluted in $95 \%$ ethanol) on day 12 after differentiation. After $48 \mathrm{~h}$ of treatment, supernatant was removed and cells were used for triacylglycerol (TG) determination and RNA extraction.

\section{Triacylglycerol content}

For TG determination, cells were washed with phosphate buffer saline (PBS) and incubated 3 times with $800 \mu \mathrm{L}$ of hexane/isopropanol (2:1). The total volume was evaporated under nitrogen, and the pellet was resuspended in $100 \mu \mathrm{L}$ of Triton X-100 in 1\% distilled water. Afterward, TG were solubilized by a sonicator, and the content was measured using infinity triglycerides reagent (Spinreact, Girona, Spain). For protein determination, cells were lysed in $0.3 \mathrm{~N} \mathrm{NaOH}$ and $0.1 \%$ SDS. Protein measurements were performed using the BCA reagent (Thermo Fischer Scientific, Rockford, USA).

\section{Extraction and analysis of RNA and quantification by real-time PCR}

RNA samples were extracted from cells treated with $25 \mu \mathrm{M}$ of each phenolic compound by using Trizol (Invitrogen, Carlsbad, CA, USA), according to the manufacturer's instructions. The integrity of the RNA extracted from all samples was verified and quantified using a 
RNA 6000 Nano Assay (Thermo Scientific, Wilmington, DE, USA). RNA samples were then treated with DNase I kit (Applied Biosystems Inc., Foster City, CA, USA) to remove any contamination with genomic DNA.

One microgram of total RNA in a total reaction volume of $20 \mu \mathrm{L}$ was reverse transcribed using the iScript cDNA Kit (Applied Biosystems Inc., Foster City, CA, USA) according to the manufacturer's protocols. Reactions were incubated initially at $25{ }^{\circ} \mathrm{C}$ for $10 \mathrm{~min}$ and subsequently at $37^{\circ} \mathrm{C}$ for $120 \mathrm{~min}$ and at $85^{\circ} \mathrm{C}$ for $5 \mathrm{~min}$.

Relative mRNA levels were quantified using real-time PCR with an iCycler MyiQ Real Time PCR Detection System (Bio-Rad, Hercules, CA, USA). 18S mRNA levels were similarly measured and served as the reference gene. The PCR reagent mixture consisted of $4.75 \mu \mathrm{L}$ of each diluted cDNA. SYBR Green Master Mix (Applied Biosystems, Foster City, CA, USA) and of the upstream and downstream primers (300 nM). Specific primers for c/ebp $\beta$ (CCAAT/enhancer-binding protein beta), $c /$ ebpa (CCAAT/enhancer-binding protein alpha), ppary (peroxisome proliferator factor gamma), srebp1c (sterol regulatory element-binding protein 1c), acc (acetyl-CoA carboxylase), perilipin, scd1 (stearoyl-CoA desaturase 1), atgl (adipose triglyceride lipase), $h s l$ (hormone sensitive lipase), fasn (fatty acid synthase) and dgat (diglyceride acyltransferase) were synthesized commercially and the sequences are shown in Table 1.

PCR parameters were as follows: initial $2 \mathrm{~min}$ at $50^{\circ} \mathrm{C}$, denaturation at $95^{\circ} \mathrm{C}$ for $10 \mathrm{~min}$ followed by 40 cycles of denaturation at $95^{\circ} \mathrm{C}$ for $30 \mathrm{~s}$, annealing at $60{ }^{\circ} \mathrm{C}$, except $64.5^{\circ} \mathrm{C}$ for $s c d 1$ and $66.3^{\circ} \mathrm{C}$ for $d g a t$, for $30 \mathrm{~s}$, and extension at $60{ }^{\circ} \mathrm{C}$ for $30 \mathrm{~s}$. The results are expressed as fold changes of threshold cycle $(\mathrm{Ct})$ value relative to controls using the $2^{-\Delta \Delta \mathrm{Ct}}$ method [25].

\section{Cytotoxicity assay}

Cell viability was assessed using the neutral red assay (TOX4 kit, Sigma-Aldrich, St. Louis, MO, USA) following manufacturer's recommendations.

\section{Statistical analysis}

Results are expressed as mean \pm SEM. Statistical analysis was performed using SPSS 24.0 (SPSS, Chicago IL, USA). Comparisons between each treatment and the controls were carried out by Student's $t$ test. Statistical significance was set at the $P<0.05$ level.

\section{Results}

Effect of apigenin, hesperidin and kaempferol on triacylglycerol content and cell viability in $\mathrm{hMSC}$-derived adipocytes during differentiation

While apigenin did not decrease TG content, hesperidin induced a decrease at both 10 and $25 \mu \mathrm{M}$ and kaempferol
Table 1 Primer sequences for PCR amplification of each gene studied

\begin{tabular}{|c|c|c|}
\hline & Sense primer & Antisense primer \\
\hline$c l e b p \beta$ & 5'-GGCAGCACCACGACTTCCT-3' & 5'-CGCCCCAGGCTCACGTAG-3' \\
\hline clebpa & 5'-AGGGTCTCTAGTTCCACGCC-3' & 5'-CAAGGGGAAGCCCAGCCTATA-3' \\
\hline ppary & $\begin{array}{l}\text { 5'-TAGATGACAGCGACTTGGCAA } \\
\text { TAT-3' }\end{array}$ & $\begin{array}{l}\text { 5'-GAATGTCTTCAATGGGCTTCA } \\
\text { CA-3' }\end{array}$ \\
\hline srebp1c & 5'-ACGCCCCACTTCATCAAGG-3' & 5'-ACTGTTGCCAAGATGGTTCCG-3' \\
\hline acc & $\begin{array}{l}\text { 5'-CATCAGCAGAGACTACGTCCT } \\
\text { CAA-3' }\end{array}$ & 5'-CATGGCAACCTCTGGATTGG-3' \\
\hline perilipin & $\begin{array}{l}\text { 5'-TGGAGACTGAGGAGAAC } \\
\quad \text { AAG-3' }\end{array}$ & 5'-ATGTCACAGCCGAGATGG-3' \\
\hline scdl & 5'-GCAGGACGATATCTCTAGCT-3' & $\begin{array}{l}\text { 5'-GTCTCCAACTTATCTCCTCCA } \\
\text { TTC-3' }\end{array}$ \\
\hline atgl & 5'-GTGTCAGACGGCGAGAATG -3' & 5'-TGGA GGGAGGGAGGGATG-3' \\
\hline hsl & 5'-TCAGTGTCTAGGTCAGACTGG-3' & 5'-AGGCTTCTGTTGGGTATTGGA-3' \\
\hline fasn & $\begin{array}{l}\text { 5'-TATGCTTCTTCGT- } \\
\text { GCAGCAGTT-3' }\end{array}$ & 5'-GCTGCCACACGCTCCTCTAG-3' \\
\hline dgat & 5'-ATTGCTGGCTCATCGCTGT-3' & $\begin{array}{l}\text { 5'-GGGAAAGTAGTCTCGAAAGTA } \\
\text { GC-3' }\end{array}$ \\
\hline 185 & 5'-TTCGAACGTCTGCCCTATCAA-3' & 5'-ATGGTAGGCACGGCGACTA-3' \\
\hline
\end{tabular}

c/ebp $\beta$, CCAAT/enhancer-binding protein beta; c/ebpa, CCAAT/enhancerbinding protein alpha; ppary, peroxisome proliferator fator gamma; srebp1c, sterol regulatory element-binding protein 1c; acc, acetyl-CoA carboxylase; scd1, stearoyl-CoA desaturase $1 ;$ atgl, adipose triglyceride lípase; $h s l$, hormone sensitive lípase; fasn, fatty acid synthase; dgat, diglyceride acyltransferase

at the three doses used (Fig. 1a-c). Apigenin, hesperidin or kaempferol did not produce a loss of viability of hMSCs even when exposed to the highest concentration of each compound ( $25 \mu \mathrm{M})$ (Fig. 2).

\section{Effect of apigenin, hesperidin and kaempferol in hMSC-derived adipocytes during differentiation}

On day 3 , the expression of $c / e b p \beta$ and ppary was measured in cells treated with the three phenolic compounds at $25 \mu \mathrm{M}$. Apigenin did not modify the expression of these genes. By contrast, hesperidin-treated cells showed lower mRNA levels of both genes. In the case of kaempferol, cells showed a significantly reduction in ppary gene expression and a trend towards lower values in the case of $c / e b p \beta(P=0.06)$ (Fig. 3).

On day 8 , apigenin did not modify $c / e b p \beta$ gene expression, while hesperidin and kaempferol-treated cells showed lower mRNA levels than the control cells (Fig. 4). Furthermore, gene expression of transcription factors involved in the intermediate stage of adipogenesis, $c /$ ebpo, ppary and srebp1c, is presented in Fig. 5. Only hesperidin significantly reduced srebp $1 c$ mRNA levels. Regarding the late stage of adipogenesis, acc, perilipin and $s c d 1$ gene expression was determined. Apigenin reduced acc and perilipin gene expression. In turn, hesperidin induced a reduction in perilipin mRNA levels (Fig. 6). 


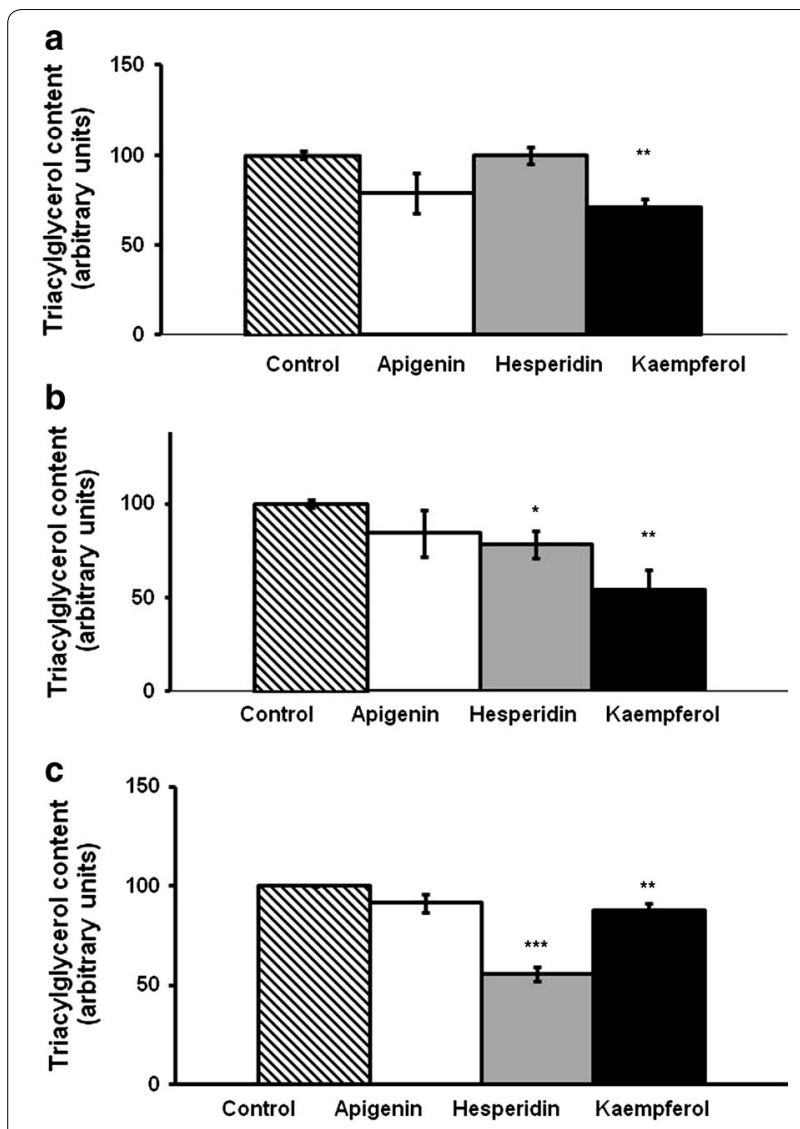

Fig. 1 Triacylglycerol content in maturing pre-adipocytes derived from human mesenchymal stem cells treated with apigenin, hesperidin or kaempferol $1 \mu \mathrm{M}(\mathbf{a}), 10 \mu \mathrm{M}(\mathbf{b})$ or $25 \mu \mathrm{M}$ (c) or not (control cells) for 8 days. Values are mean \pm SEM. Comparisons between each treatment and the control were analyzed by Student's $t$ test. Asterisks represent differences between phenolic compounds-treated cells and control cells. ${ }^{*} P<0.05 ;{ }^{* *} P<0.01 ;{ }^{* * *} P<0.001$

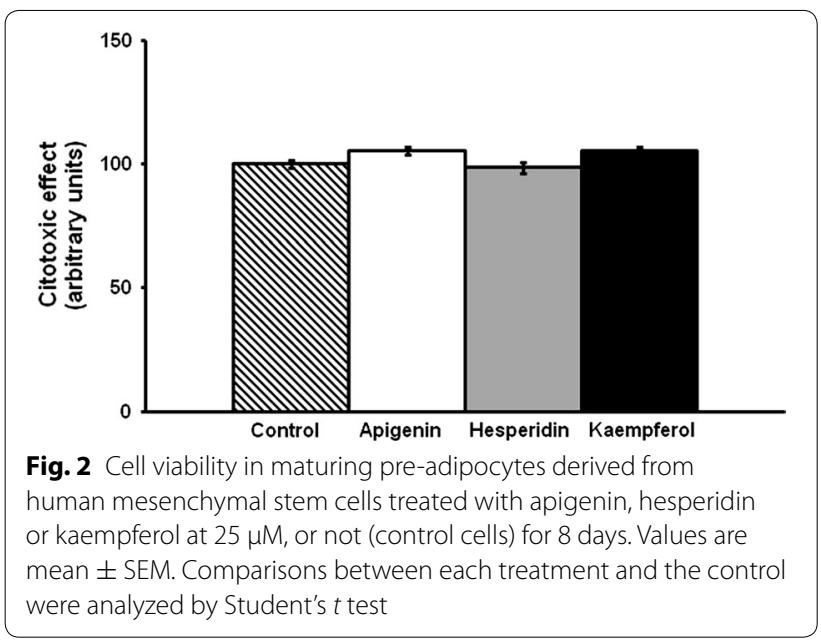

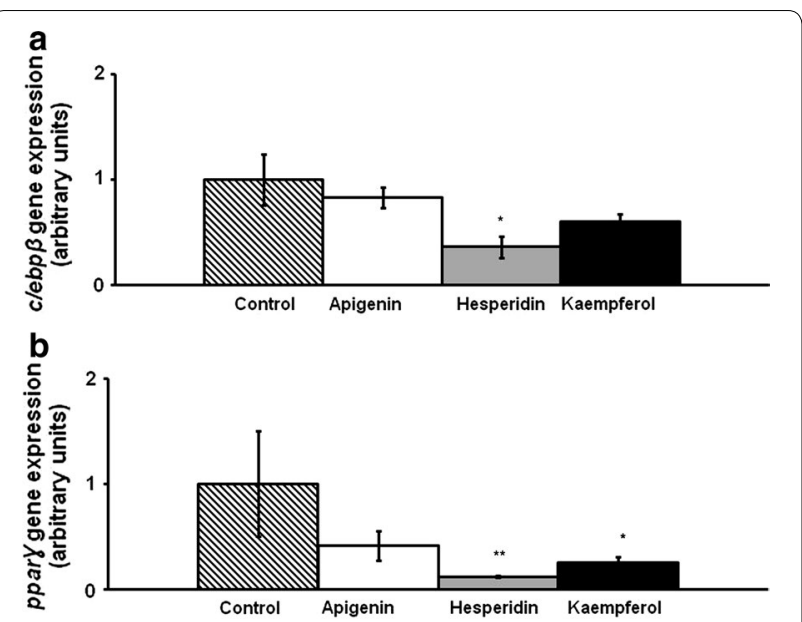

Fig. 3 clebp $\beta$ (a) and ppary (b) gene expression in maturing preadipocytes derived from human mesenchymal stem cells treated with apigenin, hesperidin or kaempferol at $25 \mu \mathrm{M}$ or not (control cells) for 3 days. Values are mean \pm SEM. Comparisons between each treatment and the control were analyzed by Student's $t$ test. ${ }^{*} P<0.05$ ${ }^{* *} P<0.01$

\section{Effect of apigenin, hesperidin and kaempferol} on triacylglycerol content in mature adipocytes derived from hMSCs

The lowest doses, 1 and $10 \mu \mathrm{M}$ of apigenin, hesperidin or kaempferol did not reduce TG content in mature adipocytes (Fig. 7a and b). However, $25 \mu \mathrm{M}$ of the three phenolic compounds led to a significant diminution of TG (Fig. 7c).

\section{Effect of apigenin, hesperidin and kaempferol on gene expression of mature adipocytes derived from hMSCs} Gene expression in mature adipocytes was measured at $25 \mu \mathrm{M}$. The three compounds increased atgl mRNA levels (Fig. 8a). In addition, apigenin and hesperidin decreased gene expression of fasn (Fig. 8e). No changes were observed in the expression of $h s l$, acc, dgat2 and scd1 (Fig. 8b-d, f).

\section{Discussion}

In recent years, a large number of scientific studies have focused on phenolic compounds as potential new tools for obesity management. In this context, our group previously analyzed the effect of fifteen phenolic compounds, belonging to different chemical groups, on 3T3-L1 preadipocytes, in order to know the potential relationship between the efficacy on adipogenesis inhibition and the chemical structure [23].

The present work aimed to study the responses of human pre-adipocytes and adipocytes obtained from 


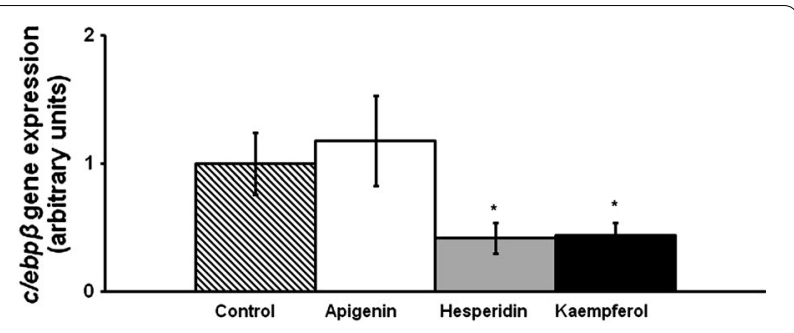

Fig. $4 \mathrm{clebp} \beta$ gene expression in maturing pre-adipocytes derived from human mesenchymal stem cells treated with apigenin, hesperidin or kaempferol at $25 \mu \mathrm{M}$ or not (control cells) for 8 days. Values are mean \pm SEM. Comparisons between each treatment and the control were analyzed by Student's $t$ test. ${ }^{*} P<0.05$
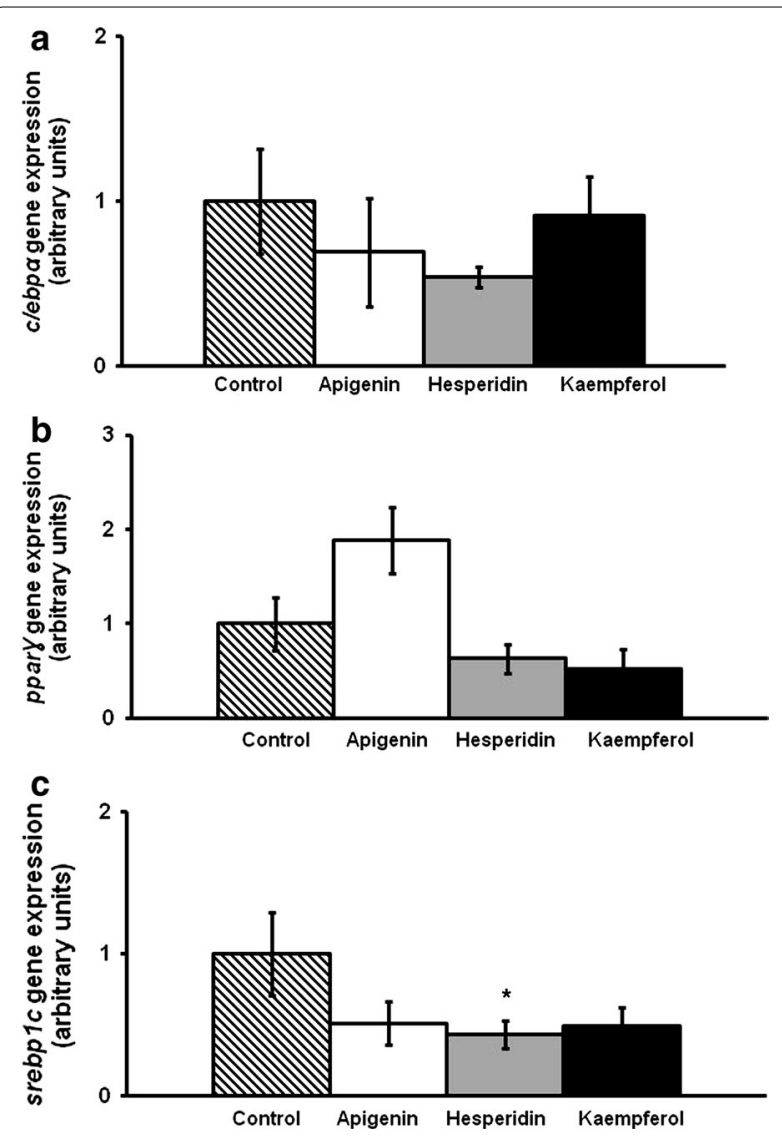

Fig. 5 clebpa (a), ppary (b) and srebplc (c) gene expression in maturing pre-adipocytes derived from human mesenchymal stem cells treated with hesperidin or kaempferol at $25 \mu \mathrm{M}$ or not (control cells) for 8 days. Values are mean \pm SEM. Comparisons between each treatment and the control were analyzed by Student's $t$ test. ${ }^{*} P<0.05$

stem cells to three polyphenols: (a) apigenin, a natural flavonoid widely distributed in plant foods such as chamomile tea, grapefruit, onions, oranges and some spices like parsley, (b) hesperidin, a flavanone glycoside abundant in citrus fruits and (c) kaempferol, a natural flavonol originally isolated from tea, broccoli and other plant sources, and to compare them with those obtained previously in murine adipocytes under the same experimental conditions. We selected these three compounds because they showed greater effectiveness in our previous study carried out in 3T3-L1 [18] and because their mechanisms of action have been little studied. We carried out the experiment in a range from a physiological dose of $1 \mu \mathrm{M}$ [2632] to a high dose of $25 \mu \mathrm{M}$.

Apigenin did not show an anti-adipogenic action. By contrast, pre-adipocytes treated with hesperidin and kaempferol showed reduced TG content at the end of the maturation process, suggesting that these compounds induced a reduction in adipogenesis. These results are different from those obtained in our laboratory in 3T3-L1 pre-adipocytes [23]. In these cells, apigenin and kaempferol were anti-adipogenic at 10 and $25 \mu \mathrm{M}$, and hesperidin was effective at the three experimental doses. These results suggest that kaempferol, and mainly hesperidin, could be useful to prevent obesity in those stages of life where adipogenesis, significantly contributes to obesity development, such as childhood, adolescence and adults with severe levels of obesity. By comparing these results with those previously observed in 3T3-L1 preadipocytes, we can state that the latter seem to be more responsive to apigenin and hesperidin than pre-adipocyte derived from human stem cells, but not to kaempferol. This confirms the existence of important interspecies differences in adipocyte function and thus the difficulty in extrapolating results from murine adipocytes to human adipocytes.

In order to discard a potential involvement of cytotoxic effects in adipogenesis reduction, we measured cell viability when cells were incubated with the highest dose $(25 \mu \mathrm{M})$. The study showed that the molecules did not decrease cell viability. These results are in good accordance with Morikawa et al. [33] who reported no cytotoxic effect for hesperidin at $500 \mu \mathrm{M}$ in adipocytes derived from human bone marrow stromal cells. Other authors have performed experiments treating hMSCs at different doses, not using isolated phenolic compounds but plant extracts containing kaempferol, hesperidin and apigenin among other phenolic compounds [34, 35]. The only toxic effect was observed at the highest doses used (above $0.5 \mathrm{mg} / \mathrm{mL}$ ). The authors concluded that this effect might be due to synergism between compounds present in the plant extract.

One of the objectives of the present study was to elucidate the mechanism by which apigenin, hesperidin and kaempferol reduced adipogenesis, and for that purpose the expression of genes involved in this pathway was analyzed. Three phases can be distinguished in adipogenesis: early, intermediate and late [36]. During clonal expansion, there is an induction of the early phase 


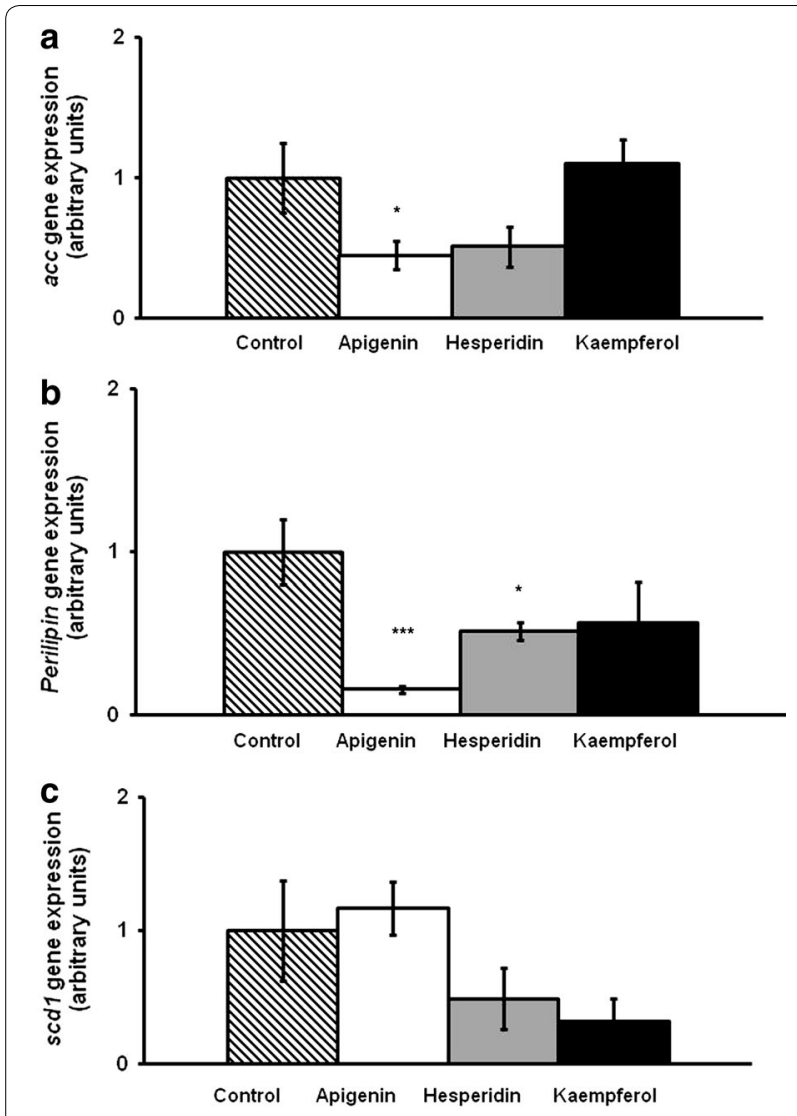

Fig. 6 acc (a), perilipin (b) and scd1 (c) gene expression in maturing pre-adipocytes derived from human mesenchymal stem cells treated with apigenin, hesperidin or kaempferol at $25 \mu \mathrm{M}$ or not (control cells) for 8 days. Values are mean \pm SEM. Comparisons between each treatment and the control were analyzed by Student's $t$ test. ${ }^{*} P<0.05$; ${ }^{* *} P<0.01$ transcription factor, $c / e b p \beta$, which leads to transactivation of the transcription factors of the intermediate stage ppary, c/ebpo and srebp1c [36]. During the late phase of differentiation, adipocytes markedly increase de novo lipogenesis and acquire sensitivity to insulin. The mRNA levels of enzymes involved in TG metabolism, including acc and scd1 among others, increase 10-100 fold. The transcription factors of the intermediate stage are implicated in the activation of these last genes [37].

Under our experimental conditions, apigenin did not modify the expression of the main adipogenic genes $(c /$ $e b p \beta, c / e b p \alpha$, ppary and srebp1c) [38]. This is in good accordance with the observed lack of reduction in TG content. As far as we know, there are no studies in the literature on human adipocytes derived from stem cells treated with this phenolic compound, and thus comparisons cannot be made. By contrast, in 3T3-L1 pre-adipocytes many authors analyzed the anti-adipogenic effect of this phenolic compound. Kim et al. [39], observed that
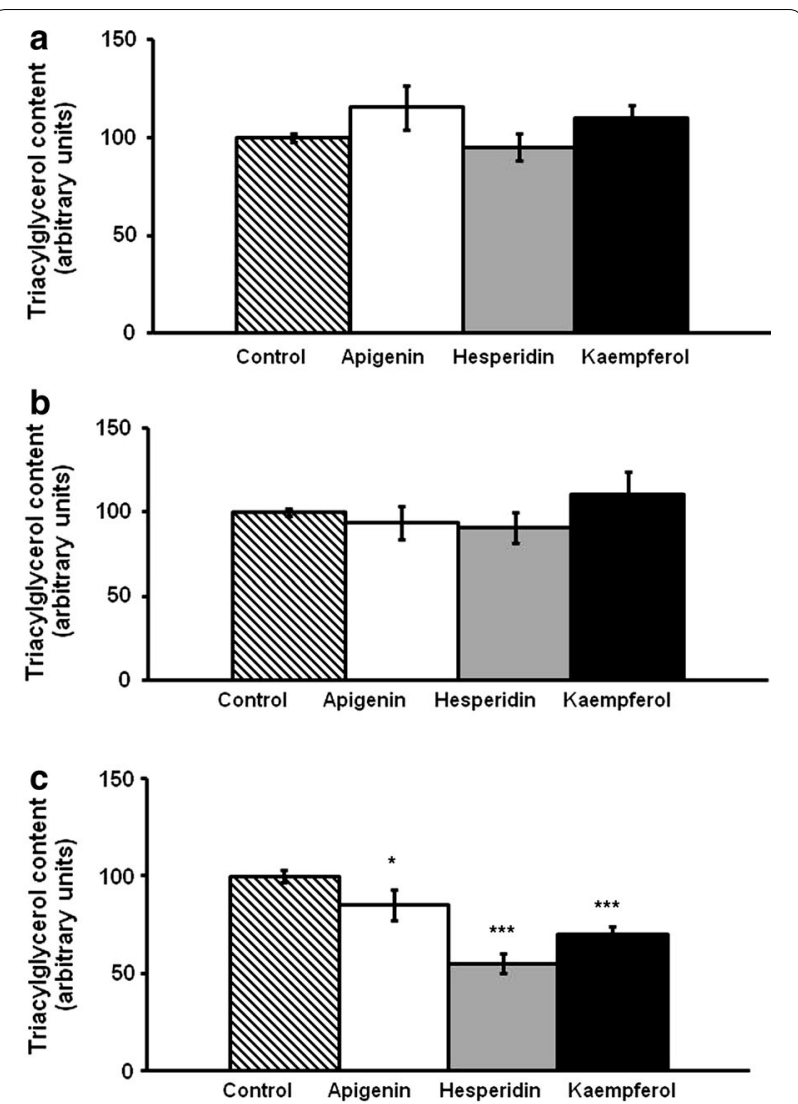

Fig. 7 Triacylglycerol content in mature adipocytes derived from human mesenchymal stem cells treated with apigenin, hesperidin or kaempferol $1 \mu \mathrm{M}(\mathbf{a}), 10 \mu \mathrm{M}(\mathbf{b})$ or $25 \mu \mathrm{M}$ (c) or not (control cells) for $48 \mathrm{~h}$. Values are mean \pm SEM. Comparisons between each treatment and the control were analyzed by Student's t test. Asterisks represent differences between phenolic compounds-treated cells and control cells. ${ }^{*} \mathrm{P}<0.05$; ${ }^{* *} \mathrm{P}<0.01$; ${ }^{* *} \mathrm{P}<0.001$

$70 \mu \mathrm{M}$ apigenin reduced cell TG content by modulating the expression of the adipogenic transcriptional factors $\mathrm{C} / \mathrm{EBP} \beta, \mathrm{PPAR} \gamma$ and $\mathrm{C} / \mathrm{EBP} \alpha$. These results are in good accordance with that of Ono et al. [40], who observed an anti-adipogenic effect of apigenin at 10 and $50 \mu \mathrm{M}$, but not at $1 \mathrm{mM}$. In our laboratory we analyzed the effect of this compound on 3T3-L1 cells in the same experimental conditions, and we observed reductions in TG content when incubations were carried out with 10 and $25 \mu \mathrm{M}$ [23]. Other authors did not observe a reduction in TG content in the same cells at a dose of $10 \mu \mathrm{M}$ [41].

Hesperidin inhibited genes involved in the three phases of adipogenesis, $c / e b p \beta$ srebp $1 c$, ppary and perilipin. These results justify the reduction in TG content induced by this phenolic compound. To the best of our knowledge, there are no in vitro studies analyzing the anti-adipogenic effect of pure hesperidin in pre-adipocytes derived from hMSCs. There is a study performed with an extract of Citrus bergamia, which contains 13\% 

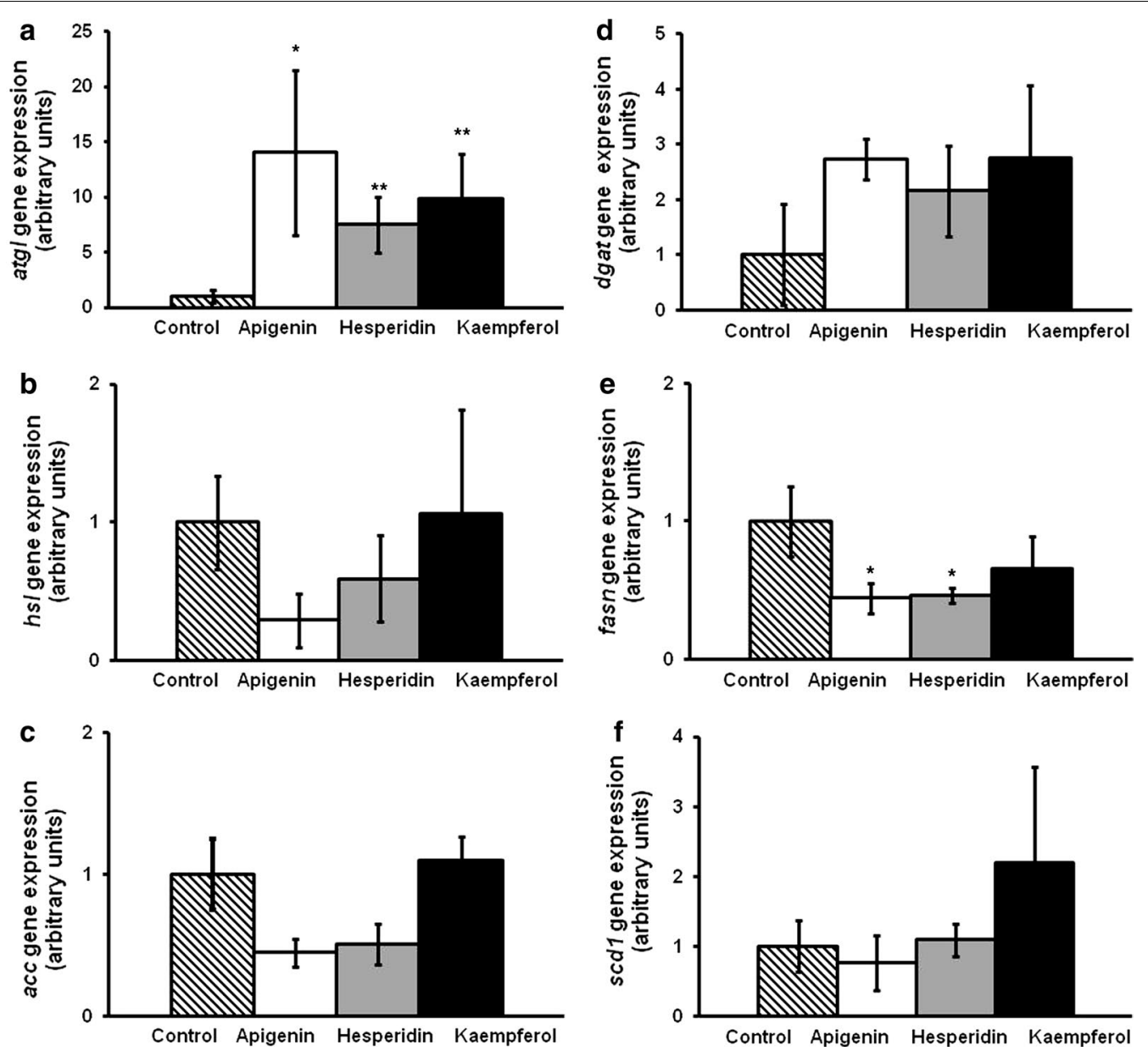

Fig. 8 Atgl (a), hsl (b), acc (c), fasn (d), dgat (e) and scd1 (f) gene expression in mature adipocytes derived from hMSCs17 stem cells treated with hesperidin or kaempferol at $25 \mu \mathrm{M}$ or not. Values are mean \pm SEM. Comparisons between each treatment and the control were analyzed by Student's $t$ test. ${ }^{*} P<0.05$; ${ }^{* *} P<0.01$

hesperidin, where hMSCs treated during differentiation showed a significant reduction in TG accumulation and ppary expression [34]. Nevertheless, the comparison with our results is difficult because the amount of hesperidin provided to the cells in that study is far lower than that used in our experiment. In addition, it contains other phenolic compounds that may also have an effect on pre-adipocytes and interact among themselves. In 3T3-L1 pre-adipocytes, Jeon et al. [42], in good accordance with our results, observed a delipidating effect in pre-adipocytes treated with 10 and $20 \mu \mathrm{M}$ hesperidin. Moreover, in our laboratory we observed a decrease in TG content in this type of cells when they were incubated for 8 days with 1, 10 or $25 \mu \mathrm{M}$. The effect was mediated by a decrease in srebp1c [23].

As far as kaempferol-treated cells are concerned, despite only $c / e b p \beta$ and ppary being significantly reduced, an anti-adipogenic effect was observed, suggesting that the inhibition of genes involved in the early and intermediate stages of adipogenesis was enough to reduce this process. In fact, a similar situation took place in a previous study from our laboratory when 3T3-L1 pre-adipocytes were incubated with resveratrol or some of its metabolites [15]. As far as we are aware, there are no studies in the literature that demonstrate the antiadipogenic effect of this compound in adipocytes derived from hMSCs. In 3T3-L1 pre-adipocytes, doses higher than $5 \mu \mathrm{M}$ of kaempferol exerted a significant anti-adipogenic effect [43]. Moreover, it was observed that also at $40 \mu \mathrm{M}$, this compound decreased TG accumulation by the down-regulation of ppary and srebp1c [44]. In our studies performed in this type of cells, kaempferol reduced TG content at 10 and $25 \mu \mathrm{M}$, but not at $1 \mu \mathrm{M}$. The effect was mediated by a decrease in $c / e b p \beta$ and srebp1c [23].

The present study also aimed to determine the effect of the three phenolic compounds in mature adipocytes. All of them reduced TG accumulation at the dose of $25 \mu \mathrm{M}$ 
after $48 \mathrm{~h}$ of treatment, but not at lower doses. Taking into account that $25 \mu \mathrm{M}$ is far higher than the serum concentrations and tissue amounts found in animals treated with polyphenols, we may say that in all likelihood these phenolic compound are not useful to reduce body fat accumulation in adult humans. Unfortunately, there are no studies in the literature showing the effects of pure apigenin, hesperidin or kaempferol on mature adipocytes derived from hMSCs. As far as plant extracts containing these phenolic compounds are concerned, Lo Furno et al. [34] showed that treating hMSCs cells with 10 or $100 \mu \mathrm{g} /$ $\mathrm{mL}$ of C. bergamia extract during 7 or 14 days reduced TG accumulation. Colitti et al. [45] demonstrated that a plant extract from Citrus aurantium, containing hesperidin, reduced lipid accumulation in primary human mature adipocytes.

When the expression of genes involved in TG metabolism of mature adipocytes was analyzed, all compounds increased mRNA levels of a very well known lipase, atgl. By contrast, $h s l$ remained unchanged. This could be explained by the fact that $h s l$ mediates lipolysis stimulated by catecholamines and by natriuretic peptide, whereas atgl mediates the hydrolysis of TG during basal lipolysis [46]. Moreover, apigenin and hesperidin decreased gene expression of fasn. These results as a whole suggest that while the three compounds reduced TG content in mature human adipocytes by affecting, at least in part, the lipolytic process, in the case of apigenin the decrease in the lipogenic pathway also contributed to the delipidating effect.

This is the first time that the effect of pure apigenin, hesperidin and kaempferol has been tested in mature adipocytes derived from hMSCs. However, in the study of Lo Furno et al. [34], where C. bergamia extracts were used to treat hMSCs for 14 days, the authors observed that 10 and $100 \mu \mathrm{g} / \mathrm{mL}$ of the plant extract increased lipase protein levels, results that are in line with those of the present study [27]. As explained previously in this manuscript, a comparison with our results is difficult because of the presence of other active phenolic compounds and the potential synergism.

\section{Conclusions}

In summary, the present study shows the anti-adipogenic and delipidating effects of apigenin, hesperidin and kaempferol in human adipocytes derived from hMSCs for the first time. While hesperidin and kaempferol reduce adipogenesis, apigenin was ineffective. Regarding mature adipocytes, the three compounds (hesperidin, kaempferol and apigenin) reduce TG accumulation by activating, at least in part, lipolysis, and in the case of hesperidin and apigenin, also by reducing lipogenesis. Nevertheless, doses higher than those found in serum and plasma of animals treated with polyphenols are needed to show the delipidating effect in mature adipocytes.

\section{Abbreviations}

acc: acetyl-CoA carboxylase; atgl: adipose triglyceride lipase; Ct: threshold cycle; dgat: diglyceride acyltransferase; clebpa: CCAAT/enhancer-binding protein alpha; c/ebp $\beta$ : CCAAT/enhancer-binding protein beta; fasn: fatty acid synthase; FBS: fetal bovine serum; hsl: hormone sensitive lipase; MSC: mesenchymal stem cells; PBS: phosphate buffer saline; ppary: peroxisome proliferator factor gamma; scd1: stearoyl-CoA desaturase 1; srebp 1c: sterol regulatory element-binding protein 1c; TG: triacylglycerol.

\section{Authors' contributions}

SGZ, AL, NA, AMS carried out experiments; AFQ performed experimental design and supervised results; MPGS obtained and isolated stem cells; MPO, JMAM wrote the manuscript and coordinated experiments. All authors read and approved the final manuscript.

\section{Author details}

${ }^{1}$ Nutrition and Obesity Group, Department of Nutrition and Food Science and Lucio Lascaray Research Center, University of the Basque Country (UPV/ EHU), Vitoria, Spain. ${ }^{2}$ Adipocyte and Fat Biology Laboratory (AdipoFat), Unidad de Investigación Traslacional, Instituto Aragonés de Ciencias de la Salud (IACS), Instituto de Investigación Sanitaria (IIS) Aragón, Zaragoza, Spain. ${ }^{3}$ CIBER Fisiopatología Obesidad y Nutrición (CIBERobn), Instituto de Salud Carlos III, Madrid, Spain

\section{Acknowledgements}

Not applicable.

\section{Competing interests}

The authors declare that they have no competing interests.

\section{Availability of data and materials}

The datasets used and/or analysed during the current study are available from the corresponding author on reasonable request.

\section{Consent for publication}

Not applicable.

Declarations

Not applicable.

\section{Ethics approval and consent to participate}

The study was approved by Clinical Investigation Ethics Committee of Aragon (Acta 11/2013).

\section{Funding}

This study was supported by grants from the Instituto de Salud Carlos III (CIBERObn), Government of the Basque Country (IT-572-13) and University of the Basque Country (UPV/EHU) (ELDUNANOTEK UFI11/32). Saioa GómezZorita is a recipient of a post-doctoral fellowship from the University of the Basque Country (UPV/EHU). Jose M. Arbones-Mainar is partially funded by the Project PI14/00508 (Instituto de Salud Carlos III) and by the Fondo Europeo de Desarrollo Regional (FEDER) funds: "Una manera de hacer Europa".

\section{Publisher's Note}

Springer Nature remains neutral with regard to jurisdictional claims in published maps and institutional affiliations.

Received: 7 April 2017 Accepted: 12 November 2017

Published online: 21 November 2017 


\section{References}

1. de Ferranti S, Mozaffarian D. The perfect storm: obesity, adipocyte dysfunction, and metabolic consequences. Clin Chem. 2008;54:945-55.

2. Tang QQ, Lane MD. Adipogenesis: from stem cell to adipocyte. Annu Rev Biochem. 2012;81:715-36.

3. Vaz-da-Silva M, Loureiro A, Falcao A, Nunes T, Rocha J, Fernandes-Lopes C, Soares E, Wright L, Almeida L, Soares-da-Silva P. Effect of food on the pharmacokinetic profile of trans-resveratrol. Int J Clin Pharmacol Ther. 2008:46:564-70.

4. Rosen ED, MacDougald OA. Adipocyte differentiation from the inside out. Nat Rev Mol Cell Biol. 2006:7:885-96.

5. El-Badri N, Ghoneim MA. Mesenchymal stem cell therapy in diabetes mellitus: progress and challenges. J Nucleic Acids. 2013;2013:194858.

6. Marketou ME, Parthenakis FI, Kalyva A, Pontikoglou C, Maragkoudakis S, Kontaraki JE, Zacharis EA, Chlouverakis G, Patrianakos A, Papadaki HA, Vardas PE. Increased mobilization of mesenchymal stem cells in patients with essential hypertension: the effect of left ventricular hypertrophy. J Clin Hypertens (Greenwich). 2014;16:883-8.

7. Shen H, Wang Y, Zhang Z, Yang J, Hu S, Shen Z. Mesenchymal stem cells for cardiac regenerative therapy: optimization of cell differentiation strategy. Stem Cells Int. 2015;2015:524756.

8. Del Rio D, Rodriguez-Mateos A, Spencer JP, Tognolini M, Borges G, Crozier A. Dietary (poly) phenolics in human health: structures, bioavailability, and evidence of protective effects against chronic diseases. Antioxid Redox Signal. 2013;18:1818-92.

9. Eseberri I, Miranda J, Lasa A, Churruca I, Portillo MP. Doses of quercetin in the range of serum concentrations exert delipidating effects in 3T3-L1 preadipocytes by acting on different stages of adipogenesis, but not in mature adipocytes. Oxid Med Cell Longev. 2015;2015:480943.

10. Rayalam S, Yang J, Ambati S, Della-Fera M, Baile C. Resveratrol induces apoptosis and inhibits adipogenesis in 3T3-L1 adipocytes. Phytother Res. 2008;22:1367-71.

11. Wu M, Liu D, Zeng R, Xian T, Lu Y, Zeng G, Sun Z, Huang B, Huang Q. Epigallocatechin-3-gallate inhibits adipogenesis through down-regulation of PPARY and FAS expression mediated by PI3K-AKT signaling in 3T3-L1 cells. Eur J Pharmacol. 2017;795:134-42.

12. Casado-Díaz A, Anter J, Dorado G, Quesada-Gómez JM. Effects of quercetin, a natural phenolic compound, in the differentiation of human mesenchymal stem cells (MSC) into adipocytes and osteoblasts. J Nutr Biochem. 2016:32:151-62.

13. Fischer-Posovszky P, Kukulus V, Tews D, Unterkircher T, Debatin K, Fulda S, Wabitsch M. Resveratrol regulates human adipocyte number and function in a Sirt1-dependent manner. Am J Clin Nutr. 2010;92:5-15.

14. Gomez-Zorita S, Tréguer K, Mercader J, Carpéné C. Resveratrol directly affects in vitro lipolysis and glucose transport in human fat cells. J Physiol Biochem. 2013:69:585-93.

15. Lasa A, Schweiger M, Kotzbeck P, Churruca I, Simón E, Zechner R, Portillo MP. Resveratrol regulates lipolysis via adipose triglyceride lipase. J Nutr Biochem. 2012;23:379-84

16. Leiherer A, Stoemmer K, Muendlein A, Saely CH, Kinz E, Brandtner EM, Fraunberger $\mathrm{P}$, Drexel H. Quercetin impacts expression of metabolismand obesity-associated genes in SGBS adipocytes. Nutrients. 2016:8:282

17. Les F, Deleruyelle S, Cassagnes LE, Boutin JA, Balogh B, Arbones-Mainar JM, Biron S, Marceau P, Richard D, Nepveu F, et al. Piceatannol and resveratrol share inhibitory effects on hydrogen peroxide release, monoamine oxidase and lipogenic activities in adipose tissue, but differ in their antilipolytic properties. Chem Biol Interact. 2016;258:115-25.

18. Park H, Yang J, Ambati S, Della-Fera M, Hausman D, Rayalam S, Baile C. Combined effects of genistein, quercetin, and resveratrol in human and 3T3-L1 adipocytes. J Med Food. 2008;11:773-83.

19. Warnke I, Jocken JW, Schoop R, Toepfer C, Goralczyk R, Schwager J. Combinations of bio-active dietary constituents affect human white adipocyte function in-vitro. Nutr Metab (Lond). 2016;13:84.

20. Entenmann $\mathrm{G}$, Hauner $\mathrm{H}$. Relationship between replication and differentiation in cultured human adipocyte precursor cells. Am J Physiol. 1996;270:C1011-6.

21. Janderová L, McNeil M, Murrell AN, Mynatt RL, Smith SR. Human mesenchymal stem cells as an in vitro model for human adipogenesis. Obes Res. 2003;11:65-74.

22. Nakamura M, Toyama Y. Transplantation of neural stem cells into spinal cord after injury. Nihon Rinsho. 2003;61:463-8.
23. Mosqueda-Solís A, Lasa A, Gómez-Zorita S, Eseberri I, Picó C, Portillo MP. Screening of potential anti-adipogenic effects of phenolic compounds showing different chemical structure in 3T3-L1 preadipocytes. Food Funct. 2017;8:3576-86.

24. Perez-Diaz S, Garcia-Rodriguez B, Gonzalez-Irazabal Y, Valero M, LagosLizan J, Arbones-Mainar JM. Knockdown of PTRF ameliorates adipocyte differentiation and functionality of human mesenchymal stem cells. Am J Physiol Cell Physiol. 2017;312:C83-91.

25. Livak K, Schmittgen T. Analysis of relative gene expression data using realtime quantitative PCR and the 2(-Delta Delta C(T)) method. Methods. 2001:25:402-8.

26. Kanaze FI, Bounartzi MI, Georgarakis M, Niopas I. Pharmacokinetics of the citrus flavanone aglycones hesperetin and naringenin after single oral administration in human subjects. Eur J Clin Nutr. 2007;61:472-7.

27. Jin MJ, Kim U, Kim IS, Kim Y, Kim DH, Han SB, Kim DH, Kwon OS, Yoo HH. Effects of gut microflora on pharmacokinetics of hesperidin: a study on non-antibiotic and pseudo-germ-free rats. J Toxicol Environ Health Part A. 2010:73:1441-50

28. Chang L, Ren Y, Cao L, Sun Y, Sun Q, Sheng N, Yuan L, Zhi X, Zhang L. Simultaneous determination and pharmacokinetic study of six flavonoids from Fructus Sophorae extract in rat plasma by LC-MS/MS. J Chromatogr B. 2012;904:59-64.

29. Sun H, Dong T, Zhang A, Yang J, Yan G, Sakurai T, Wu S, Han Y, Wang X. Pharmacokinetics of hesperetin and naringenin in the Zhi Zhu Wan, a traditional chinese medicinal formulae, and its pharmacodynamics study. Phytother Res. 2013;27:1345-51.

30. Zhou Z, Wang M, Guo Z, Zhang X. Pharmacokinetic evaluation of the interaction between oral kaempferol and ethanol in rats. Acta Pharm. 2016:66:563-8

31. Dong X, Lan W, Yin X, Yang C, Wang W, Ni J. Simultaneous determination and pharmacokinetic study of quercetin, luteolin, and apigenin in rat plasma after oral administration of Matricaria chamomilla L. extract by HPLC-UV. Evid Based Complement Altern Med. 2017:2017:8370584.

32. Elhennawy MG, Lin HS. Quantification of apigenin trimethyl ether in rat plasma by liquid chromatography-tandem mass spectrometry: application to a pre-clinical pharmacokinetic study. J Pharm Biomed Anal. 2017;142:35-41.

33. Morikawa K, Nonaka M, Mochizuki H, Handa K, Hanada H, Hirota K. Naringenin and hesperetin induce growth arrest, apoptosis, and cytoplasmic fat deposit in human preadipocytes. J Agric Food Chem. 2008;56:11030-7

34. Lo Furno D, Graziano AC, Avola R, Giuffrida R, Perciavalle V, Bonina F, Mannino G, Cardile V. A Citrus bergamia extract decreases adipogenesis and increases lipolysis by modulating PPAR levels in mesenchymal stem cells from human adipose tissue. PPAR Res. 2016;2016:4563815.

35. Yunita O, Mochammad Yuwono M, Rantam FA. In vitro cytotoxicity assay of Sauropus androgynus on human mesenchymal stem cells. J Toxicol Environ Chem. 2013;95:679-86.

36. Ntambi J, Young-Cheul K. Adipocyte differentiation and gene expression. J Nutr. 2000;130:3122S-6S.

37. Gregoire FM, Smas CM, Sul HS. Understanding adipocyte differentiation. Physiol Rev. 1998;78:783-809.

38. Rosen ED, Walkey CJ, Puigserver P, Spiegelman BM. Transcriptional regulation of adipogenesis. Genes Dev. 2000;14:1293-307.

39. Kim MA, Kang K, Lee HJ, Kim M, Kim CY, Nho CW. Apigenin isolated from Daphne genkwa Siebold et Zucc. inhibits 3T3-L1 preadipocyte differentiation through a modulation of mitotic clonal expansion. Life Sci. 2014;101:64-72.

40. Ono M, Fujimori K. Antiadipogenic effect of dietary apigenin through activation of AMPK in 3T3-L1 cells. J Agric Food Chem. 2011;59:13346-52.

41. Nishina A, Ukiya M, Fukatsu M, Koketsu M, Ninomiya M, Sato D, Yamamoto J, Kobayashi-Hattori K, Okubo T, Tokuoka H, Kimura H. Effects of various 5,7-dihydroxyflavone analogs on adipogenesis in 3T3-L1 cells. Biol Pharm Bull. 2015;38:1794-800.

42. Jeon HJ, Seo MJ, Choi HS, Lee OH, Lee BY. Gelidium elegans, an edible red seaweed, and hesperidin inhibit lipid accumulation and production of reactive oxygen species and reactive nitrogen species in 3T3-L1 and RAW264.7 cells. Phytother Res. 2014;28:1701-9.

43. Fang XK, Gao J, Zhu DN. Kaempferol and quercetin isolated from Euonymus alatus improve glucose uptake of 3T3-L1 cells without adipogenesis activity. Life Sci. 2008;82:615-22. 
44. Park UH, Jeong JC, Jang JS, Sung MR, Youn H, Lee SJ, Kim EJ, Um J. Negative regulation of adipogenesis by kaempferol, a component of Rhizoma Polygonati falcatum in 3T3-L1 cells. Biol Pharm Bull. 2012;35:1525-33.

45. Colitti M, Stefanon B. Different anti-adipogenic effects of bio-compounds on primary visceral pre-adipocytes and adipocytes. EXCLI J. 2016;15:362-77.
46.

Langin D, Dicker A, Tavernier G, Hoffstedt J, Mairal A, Rydén M, Arner E, Sicard A, Jenkins CM, Viguerie N, et al. Adipocyte lipases and defect of lipolysis in human obesity. Diabetes. 2005;54:3190-7.

\section{Submit your next manuscript to BioMed Central and we will help you at every step:}

- We accept pre-submission inquiries

- Our selector tool helps you to find the most relevant journal

- We provide round the clock customer support

- Convenient online submission

- Thorough peer review

- Inclusion in PubMed and all major indexing services

- Maximum visibility for your research

Submit your manuscript at

www.biomedcentral com/submit 